\title{
Direct Anterior Approach Using Navigation Improves Accuracy of Cup Position Compared to Conventional Posterior Approach
}

\author{
Jason Chow ${ }^{1}$, Simon Pearce ${ }^{1}$, Kuk-ki Cho ${ }^{2}$, William Walter ${ }^{3}$ \\ 1. Orthopaedics, Nepean Hospital 2. Orthopaedics, Royal North Shore Hospital 3. Orthopaedics, Mater \\ Hospital
}

$\square$ Corresponding author: Kuk-ki Cho, jkkcho@gmail.com

Disclosures can be found in Additional Information at the end of the article

\section{Abstract}

The accuracy of cup position in total hip arthroplasty is essential for a satisfactory result as malpositioning increases the risk of complications including dislocation, high wear rate, loosening, squeaking, edge loading, impingement and ultimately failure.

We studied 166 patients in a single-surgeon-series of matched cohorts of patients who underwent total hip arthroplasties. Four separate groups were identified comprising of the posterior approach +/- navigation and the direct anterior approach +/- navigation.

We found a significant difference between the direct anterior navigated group and the posterior non-navigated group for both anteversions ( $\mathrm{P}<0.05$, confidence interval (CI) -3.86 to -1.73 ) and inclination ( $\mathrm{P}<0.05, \mathrm{CI}-3.08$ to -1.08$)$. Almost, $72 \%$ of anterior navigated patients fell within $5^{\circ}$ of the navigation software set target cup position of $45^{\circ}$ inclination and $20^{\circ}$ anteversion and $100 \%$ were within $10^{\circ}$. Only $30 \%$ of posterior non-navigated were within $5^{\circ}$ of both anteversion and inclination and $73 \%$ were within $10^{\circ}$.

There was also a significant difference between the direct anterior navigated and nonnavigated group with respect to anteversion only ( $\mathrm{p}<0.05$, CI 1.50 to 1.30$)$. There were no other significant differences between approaches +/- navigation.

The direct anterior approach allows ease of access to both anterior-superior iliac spines for navigation and a supine patient allows anteversion and inclination to be measured in the frontal plane. We conclude that the direct anterior approach with navigation improves the

Received 04/06/2017 Review began 07/06/2017 Review ended 07/09/2017 Published 07/17/2017

\section{(c) Copyright 2017}

Chow et al. This is an open access article distributed under the terms of the Creative Commons Attribution License CC-BY 3.0., which permits unrestricted use, distribution, and reproduction in any medium, provided the original author and source are credited.
Categories: Orthopedics

Keywords: orthopaedic surgery, total hip arthroplasty, total hip replacement, intraoperative navigation, arthroplasty, outcome measures

\section{Introduction}

Improper positioning of the acetabular component in total hip arthroplasties (THA) has been shown to increase the dislocation rate [1-6], increase bearing surface wears [7-8], decrease the range of motion [9-10], increase revision rates [11] and contributes to squeaking [12]. Many 


\section{Cureus}

factors have been described which contribute to accurate cup positioning. There are patient factors including body mass index (BMI) [13], age [14-16], gender [14, 16] and primary diagnosis for total hip arthroplasty (THA) [16-17]. There are surgical factors including the performing surgeon's experience [16, 18], the surgical approach [16, 19-24], the prosthetic components [14, 16, 25-28], the acetabular cup fixation method [17] and the orientation of the acetabular cup [14, 16, 27]. We designed this study to determine if there was a difference in acetabulum orientation when performed via the direct anterior approach (DAA) or the posterior approach (PA) with and without using navigation. We studied 166 patients comparing matched cohorts who underwent THA by the same surgeon at our institution. Four separate groups of patients were identified: Group 1 - PA with navigation; Group 2 - PA without navigation; Group 3 - DAA with navigation; Group 4 - DAA without navigation. Informed consent statement was obtained for this study.

\section{Materials And Methods}

A standardized statistical computer program developed by the University of Tennessee [29] was used to perform a prospective power calculation of a continuous response variable from cohorts containing the matched patients. Prior data from an unpublished pilot study indicated a sample size of 14 pairs of subjects to reject the null hypothesis that this response difference is zero with probability (power) 0.8 . The Type I error probability associated with this test of this null hypothesis is 0.05 .

All total hip arthroplasties performed by the senior author (WLW) from January 2004 to February 2013 were analyzed retrospectively. This included 650 PA THAs and 111 DAA. Only 13 of the PA group were navigated and only 21 of the DAA group were without navigation. Due to relatively small numbers in these two groups, the study was divided into two arms. Both arms matched patients according to gender, side, body mass index (BMI) and age. The first arm contained the 13 PA navigated group which was matched to 48 PA without navigation and 33 DAA with navigation (Table 1). The second arm contained the 21 DAA without navigation group which was matched to 26 PA without navigation and 25 DAA with navigation (Table 2).

\begin{tabular}{|c|c|c|c|}
\hline Category & NAV Posterior & NO NAV Posterior & NAV Anterior \\
\hline Sex (Male:Female) & $13(8: 5)$ & $48(24: 24)$ & $33(10: 23)$ \\
\hline Body Mass Index & 30 & 29 & 29 \\
\hline Age & 65 & 70 & 71 \\
\hline
\end{tabular}

TABLE 1: Table representing the demographics of the study's first arm 


\section{Cureus}

\begin{tabular}{|c|c|c|c|}
\hline Category & NO NAV Anterior & NO NAV Posterior & NAV Anterior \\
\hline Sex (Inale:Female) & $21(4: 17)$ & $26(5: 21)$ & $25(1: 18)$ \\
\hline Body Iviass Index & 26 & 26 & 25 \\
\hline Age & 66 & 68 & 68 \\
\hline
\end{tabular}

TABLE 2: Table representing the demographics of the study's second arm

All anteroposterior (AP) hip radiographs were exported or scanned into a validated computer program and the anteversion and inclination were measured.

\section{Results}

The results of mean anteversion and inclination for all four groups are shown in Table 3, in addition to the absolute difference of these values from a target of 20 degrees anteversion and 45 degrees inclination. Box and whisker plots for all four groups are shown in Figure 1-2. A two-sample Student's T-test for two independent means was used to compare cup position within each arm of the study. Consequently, no comparison can be made between PA navigated and DAA without navigation as they were in different arms of the study. We found a significant difference between the DAA navigated group and the PA non-navigated group for both anteversions ( $\mathrm{P}<0.05$, CI -3.86 to -1.73 ) and inclination ( $\mathrm{P}<0.05$, CI -3.08 to -1.08$)$. Almost $72 \%$ of anterior navigated patients fell within 5 degrees of the target cup position of 45 degrees inclination and 20 degrees anteversion and 100\% were within 10 degrees. Only $30 \%$ of posterior non-navigated were within 5 degrees of both anteversion and inclination and $73 \%$ were within 10 degrees.

\begin{tabular}{|c|c|c|c|c|}
\hline Category & NAV Posterior & NO NAV Posterior & NAV Anterior & NO NAV Anterior \\
\hline Anteversion & $20^{\circ}$ & $18^{\circ}$ & $18^{\circ}$ & $20^{\circ}$ \\
\hline Absolute anteversion difference from $20^{\circ}$ & $4^{0}$ & $6^{\circ}$ & $3^{0}$ & $6^{\circ}$ \\
\hline Inclination & $50^{\circ}$ & $46^{\circ}$ & $47^{\circ}$ & $46^{\circ}$ \\
\hline Absolute inclination difference from $45^{\circ}$ & $5^{0}$ & $5^{\circ}$ & $3^{0}$ & $5^{\circ}$ \\
\hline
\end{tabular}

TABLE 3: Table representing the cup position for all four groups and absolute difference from the target 


\section{Cureus}

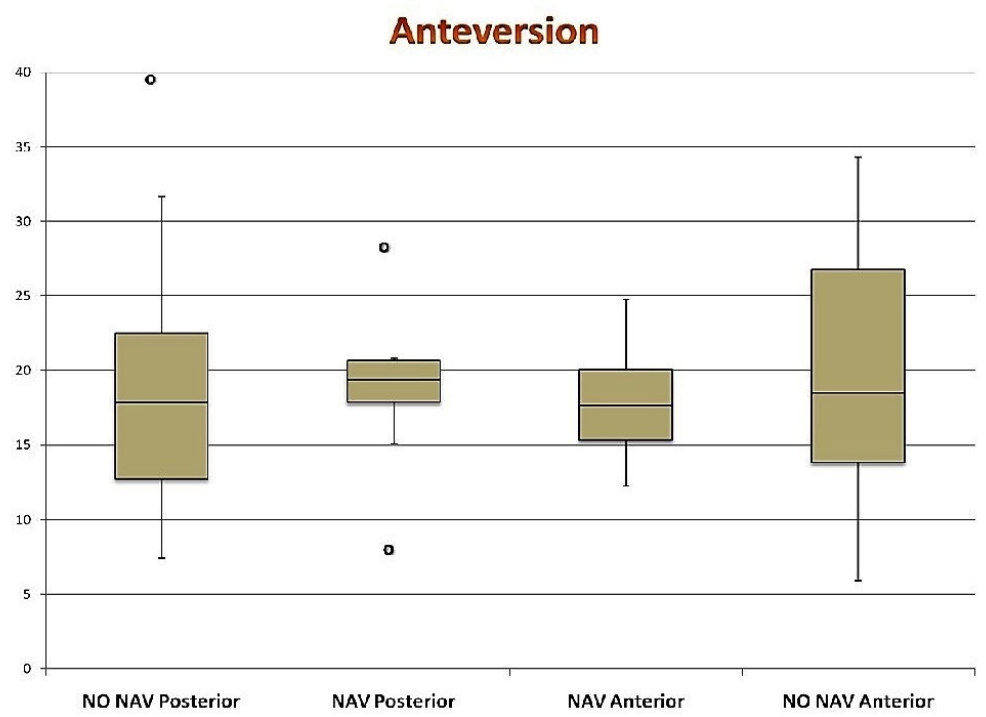

FIGURE 1: Box and whisker plot showing anteversion (degrees) in all four groups

\section{Inclination}

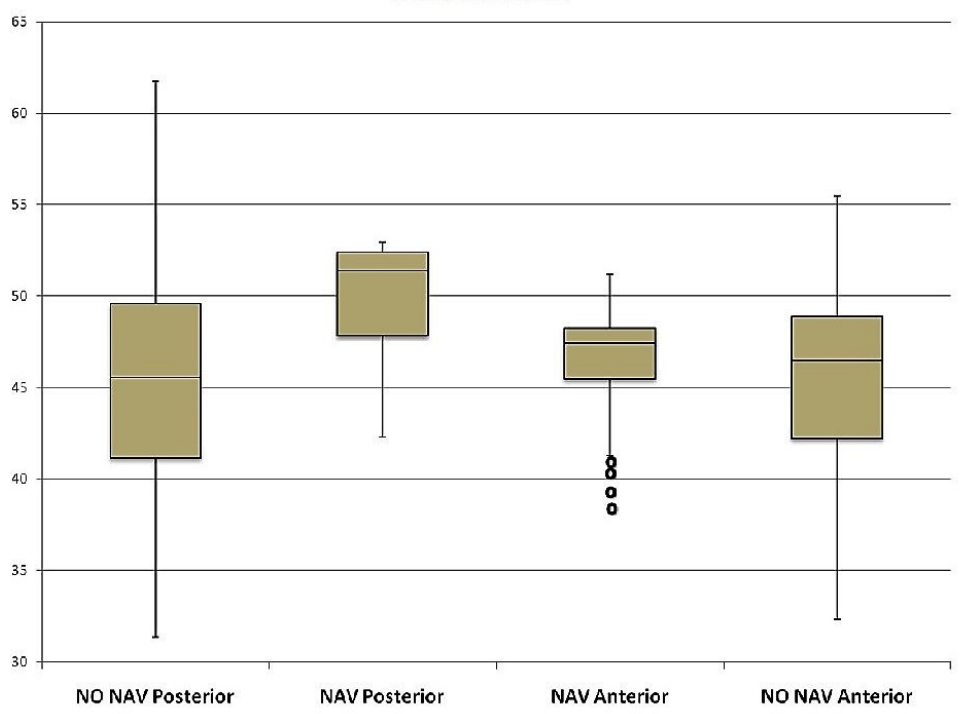

FIGURE 2: Box and whisker plot showing inclination (degrees) in all four groups

There was also a significant difference between the direct anterior navigated and nonnavigated group with respect to anteversion only ( $\mathrm{p}<0.05$, CI 1.50 to 1.30 ). There were no other significant differences between approaches $+/$ - navigation. The figure 3 shows a scatter plot comparing cup position between DAA navigated group and PA non-navigated group, which highlights the difference in precision. 


\section{Cureus}

\section{Anteversion vs Inclination for Navigation Anterior and No Navigation Posterior}

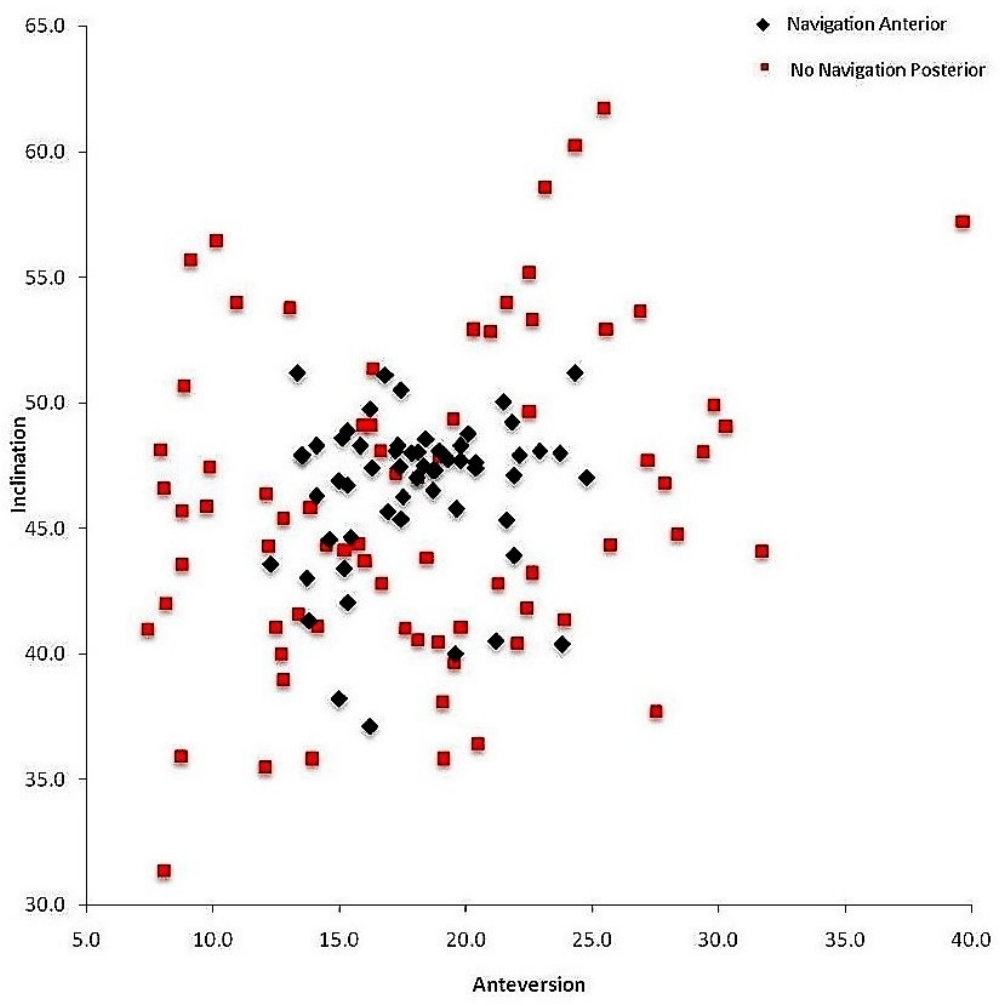

FIGURE 3: Scatterplot showing cup position of direct anterior approach (DAA) navigated vs posterior approach (PA) without navigation

\section{Discussion}

This study was designed to gain objective evidence of the accuracy of cup position whilst controlling as many of the variables as possible. All the patients were operated on by the same surgeon and all patients were rigorously matched with respect to gender, side, BMI, and age. The initial hypothesis was that the anterior approach allowed more accurate positioning of the cup for two reasons. Firstly, because it involves surgery in the frontal plane when the patient is supinely allowing an unobstructed view of both anterior superior iliac spines (ASIS) to assess the horizontal plane of the pelvis to reference off for inclination and the coronal plane of the pelvis can be inferred as being parallel to the floor to reference off for anteversion. Secondly, the supine position allows the contralateral ASIS to be prepared and draped allowing intraoperative navigation markers to be sited in a way not possible in a laterally positioned patient for the posterior approach.

There were several limitations to this study including the available numbers of patients in the two groups. The PA navigated and DAA non-navigated groups were small and did not allow for rigorous direct matching between the two groups. Since we could not draw statistical conclusion directly between these two groups, we elected to create two arms with rigorous matching between PA navigated and the two remaining groups (excluding DAA non-navigated) in one arm and the other arm containing DAA non-navigated and the two remaining groups 
(excluding PA navigated). This did not affect the comparison of PA non-navigated with DAA navigated as these were in the same arm of the study. Another potential limitation was the DAA non-navigated group included some cases in the first 30 DAA procedures that were performed by the senior author and therefore may be affected by the learning curve bias.

Our study showed that the DAA with navigation was significantly more accurate than the PA without navigation. The authors acknowledge that there is no robustly proven ideal position of the acetabular implant and the deviation from the target position of 45 degrees inclination and 20 degrees anteversion is based on the currently available literature and surgeon preference. Analysis of the level of deviation from this target revealed figures for outliers defined here as an absolute difference of greater than 10 degrees from the target position for both inclination and anteversion. Almost 72\% of DAA navigated group was accurate within 5 degrees of the target and there were no outliers, compared to 30\% of PA non-navigated group within 5 degrees and $27 \%$ were outliers.

\section{Conclusions}

The direct anterior approach with navigation is more accurate when compared to the nonnavigated posterior approach. It allows for improved visualization of the pelvic landmarks and along with the navigation, eliminates outliers and improves the accuracy of acetabular cup placement during total hip arthroplasties. The direct anterior approach with navigation allows for reproducible results and by decrease outliers hopefully, decreases the risk of potential complications related to the malposition of acetabular cups in total hip arthroplasties.

\section{Additional Information \\ Disclosures}

Human subjects: Consent was obtained by all participants in this study. Animal subjects: All authors have confirmed that this study did not involve animal subjects or tissue. Conflicts of interest: In compliance with the ICMJE uniform disclosure form, all authors declare the following: Payment/services info: All authors have declared that no financial support was received from any organization for the submitted work. Financial relationships: All authors have declared that they have no financial relationships at present or within the previous three years with any organizations that might have an interest in the submitted work. Other relationships: All authors have declared that there are no other relationships or activities that could appear to have influenced the submitted work.

\section{Acknowledgements}

The findings of this research have been summarized as an abstract in the Orthopaedic Proceedings Abstract Catalog printed on the 31st of December 2013 as a part of the collective submission following its presentation at the International Society for Technology in Arthroplasty Congress of that same year. No formal journal publications have been published using this data prior to this submission. The abstract is of the same title and can be accessed via http://www.bjjprocs.boneandjoint.org.uk/content/95-B/SUPP_34/195.

\section{References}

1. DeWal H, Su E, DiCesare PE. : Instability following total hip arthroplasty. Am J Orthop. 2003, 32:377-82.

2. Jolles BM, Zangger P, Leyvraz PF: Factors predisposing to dislocation after primary total hip arthroplasty: A multivariate analysis. J Arthroplasty. 2002, 17:282-8.

3. Lewinnek GE, Lewis JL, Tarr R, et al.: Dislocations after total hip-replacement arthroplasties . J Bone Joint Surg Am. 1978, 60:217-20. 
4. McCollum DE, Gray WJ: Dislocation after total hip arthroplasty causes, and prevention . Clin Orthop Relat Res. 1990, 261:159-70.

5. Paterno SA, Lachiewicz PF, Kelley SS: The influence of patient-related factors and the position of the acetabular component on the rate of dislocation after total hip replacement. J Bone Joint Surg Am. 1997, 79:1202-10.

6. Pierchon F, Pasquier G, Cotten A, et al.: Causes of dislocation of total hip arthroplasty. CT study of component alignment. J Bone Joint Surg Br. 1994, 76:45-8.

7. Del Schutte H Jr, Lipman AJ, Bannar SM, et al.: Effects of acetabular abduction on cup wear rates in total hip arthroplasty. J Arthroplasty. 1998, 13:621-6.

8. Kennedy JG, Rogers WB, Soffe KE, et al.: Effect of acetabular component orientation on recurrent dislocation, pelvic osteolysis, polyethylene wear, and component migration. J Arthroplasty. 1998, 13:530-4.

9. D'Lima DD, Urquhart AG, Buehler KO, et al.: The effect of the orientation of the acetabular and femoral components on the range of motion of the hip at different head-neck ratios. J Bone Joint Surg Am. 2000, 82:315-21.

10. Kummer FJ, Shah S, Iyer S, et al.: The effect of acetabular cup orientations on limiting hip rotation. J Arthroplasty. 1999, 14:509-13.

11. Sugano N, Nishii T, Miki H, et al.: Mid-term results of cementless total hip replacement using a ceramic-on-ceramic bearing with and without computer navigation. J Bone Joint Surg Br. 2007, 89:455-60.

12. Walter WL, Yeung E, Esposito C: A review of squeaking hips. J Am Acad Orthop Surg. 2010, 18:319-326.

13. Azodi SO, Adami J, Lindstrom D, et al.: High body mass index is associated with increased risk of implant dislocation following primary total hip replacement:2,106 patients followed for up to 8 years. Acta Orthop. 2008, 79:141-147.

14. Morrey BF: Difficult complications after hip joint replacement: Dislocation . Clin Orthop Relat Res. 1997, 344:179-187.

15. Newington DP, Bannister GC, Fordyce M.: Primary total hip replacement in patients over 80 years of age. J Bone Joint Surg Br. 1990, 72:450-452.

16. Sanchez-Sotelo J, Berry DJ: Epidemiology of instability after total hip replacement. . Orthop Clin North Am. 2001, 32:543-552.

17. Conroy JL, Whitehouse SL, Graves SE, et al.: Risk factors for revision for early dislocation in total hip arthroplasty. J Arthroplasty. 2008, 23:867-872.

18. Bosker BH, Verheyen CC, Horstmann WG, et al.: Poor accuracy of freehand cup positioning during total hip arthroplasty. Arch Orthop Trauma Surg. 2007, 127:375-379.

19. Arthursson AJ, Furnes O, Espehaug B, et al.: Prosthesis survival after total hip arthroplastydoes surgical approach matter? Analysis of 19,304 Charnley and 6,002 exeter primary total hip arthroplasties reported to the Norwegian Arthroplasty Register. Acta Orthop. 2007, 78:719729.

20. Colwell CWJ: Instability after total hip arthroplasty.. Curr Orthop Pract. 2009, 20:8-14.

21. Enocson ATJ, Tornkvist H, Lapidus L: Dislocation of hemiarthroplasty after femoral neck fracture: better outcome after the anterolateral approach in a prospective cohort study on 739 consecutive hips. Acta Ortho. 2008, 79:211-217.

22. Mallory TH, Lombardi AV, Fada RA, et al.: Dislocation after total hip arthroplasty using the anterolateral abductor split approach. Clin Orthop Relat Res. 1999, 358:166-172.

23. Morrey BF: Instability after total hip arthroplasty. Orthop Clin North Am. 1992, 23:237-248.

24. Bartz RL, Noble PC, Kadakia NR, et al.: The effect of femoral component head size on posterior dislocation of the artificial hip joint. J Bone Joint Surg Am. 2000, 82:1300-1307.

25. Jasty M, Goetz DD, Bragdon CR, et al.: Wear of polyethylene acetabular components in total hip arthroplasty. An analysis of one hundred and twenty-eight components retrieved at autopsy or revision operations. J Bone Joint Surg Am. 1997, 79:349-358.

26. Kelley SS, Lachiewicz PF, Hickman JM, et al.: Relationship of femoral head and acetabular size to the prevalence of dislocation. Clin Orthop Relat Res. 1998, 355:163-170.

27. Kluess D, Martin H, Mittelmeier W, et al.: Influence of femoral head size on impingement, dislocation and stress distribution in total hip replacement. Med Eng Phys. 2007, 29:465-471.

28. Muratoglu OK, Bragdon CR, O’Connor D, et al.: Larger diameter femoral heads used in conjunction with a highly cross-linked ultra-high molecular weight polyethylene: A new concept. J Arthroplasty. 2001, 16:24-30. 


\section{Cureus}

29. Dupont WD, Plummer WD: Power and sample size calculations: A review and computer program. Controlled Clin Trials. 1990, 11:116-28. 